\section{THU0198 LUMBAR SPINE INVOLVEMENT IN RHEUMATOID ARTHRITIS}

${ }^{1} \mathrm{~B}$ Moura, ${ }^{2} \mathrm{D}$ Mauget, ${ }^{1} \mathrm{M}$ Dougados. ${ }^{1}$ Rheumatology; ${ }^{2}$ Radiology, Cochin Hospital and René Descartes University, Paris, France

10.1136/annrheumdis-2001.1100

Background Lumbar spine is considered as rarely involved in rheumatoid arthritis (RA). At variance, low back pain is commonly observed and is usually thought to be related to osteoporotic vertebral fractures.

Objectives To evaluate the prevalence of both vertebral fractures and lumbar discopathy in patients with RA and low back pain.

Methods

Patients-Methods Study design: Trans-sectionnal, case control radiological study. Patients: Two groups of patients were evaluated (RA and controls), all of them were suffering from low back pain defined as any back pain of the lumbar area which had occurred during the past 10 years. RA patients (ACR criteria) were in- or out- consecutive patients. Controls were consecutive patients without inflammatory rheumatic disorders for whom lumbar spine X-rays was indicated. Outcome measures: a) vertebral fractures, b) discopathy defined as a disc space narrowing using a 4 grade scale (Kappa statistics $=0.93$ and 0.9 for intra- and inter-reproducibility, respectively). Marked discopathy was arbitrarily and a priori defined as a disc space narrowing of at least $66 \%$. Analysis: All the films were blinded for patient's identity and were allocated a number after randomization permitting an analysis by two trained observers unaware of the group of patients (i.e., RA or controls).

Results Of the 123 recruited patients, 53 were suffering for RA (57 \pm 13 years old, $79 \%$ females) and 70 defined the control group (55 \pm 13 years old, $81 \%$ females). An osteoporotic vertebral fracture was observed in 8 RA patients and never in the control group $(\mathrm{p}=0.002)$. A marked discopathy was observed in $20(38 \%)$ and in $13(19 \%)$ patients in the RA and control group respectively $(\mathrm{p}=0.017)$.

Conclusion This study confirms the higher prevalence of osteoporotic vertebral fracture in RA but also suggests that lumbar discopathy might be involved in the occurrence and severity of low back pain in RA.

\section{THU0199 RHEUMATOID ARTHRITIS: THE CORRELATION BETWEEN DESTRUCTION OF DENS EPHISTROPHEI AND SEX, RHEUMATOID FACTOR PRESENCE AND STEINBROCKER' S GRADE OF THE HANDS AND THE FEET}

M Vesela, L Sedova, J Gatterova, M Olejarova, Z Seidl, K Pavelka. Clinic of Rheumatology, Institute of Rheumatology, Prague, Czech Republic

10.1136/annrheumdis-2001.1101

\section{Background}

Objectives To find correlation between destruction of dens ephistrophei and rheumatoid factor presence, sex, Steinbrocker' $\mathrm{s}$ grade of hands and the feet.

Methods A computer analysis of 4,691 patients with polyarthritis from the database of the Institute of Rheumatology over the 2 years period (from 1998-12-01 till 2000-11-30) was done.

Totally 860 patients had $\mathrm{X}$ ray examinations made for the neck pain, the cervicocranial and/or the cervicobrachial syndrome. The $\mathrm{X}$ ray examinations of the cervical spine were made in the static and dynamic projections and were evaluated by the same radiologist. The diagnosis of RA was established in 286 cases according to ACR criteria. A group of 139 patients without radiological evidence of the cervical spine involvement was used as the control group. The rheumatoid factor (RF) was detected by the ELISA method. The $\mathrm{X}$ ray examinations of the hands and of the feet in the classical projection were classified according to Steinbrocker.

A computer analysis of 4,691 patients with polyarthritis from the database of the Institute of Rheumatology over the 2 years period (from 1998-12-01 till 2000-11-30) was done.

Totally 860 patients had $\mathrm{X}$ ray examinations made for the neck pain, the cervicocranial and/or the cervicobrachial syndrome. The $\mathrm{X}$ ray examinations of the cervical spine were made in the static and dynamic projections and were evaluated by the same radiologist. The diagnosis of RA was established in 286 cases according to ACR criteria. A group of 139 patients without radiological evidence of the cervical spine involvement was used as the control group. The rheumatoid factor (RF) was detected by the ELISA method. The $\mathrm{X}$ ray examinations of the hands and of the feet in the classical projection were classified according to Steinbrocker.

Results Patients with polyarthritis $(n=860)$ had the X ray examinations of the cervical spine for the neck pain (68\%), cervicocranial syndrome $(29 \%)$ or cervicobrachial syndrome $(3 \%)$. Radiological evidence of the cervical involvement was found in 147 patients with RA out of 286. Atlantoaxial subluxation (AAS) was found in 109 patients $(74.15 \%)$, destruction of the dens in 48 (32.65\%). The AAS and coincidental dens destruction was present in 20 patients (13.61\%) out from 147. The vertical and lateral subluxations was found only in the combinations with the ventral subluxations: ventral and vertical in 6 cases, ventral and lateral in 3 cases.

There were found positive correlations of the presence of any type of cervical spine involvement with the radiographic stage of the hands $(\mathrm{X} 2=86.51 ; \mathrm{p}<0.0001)$ and of the feet $(\mathrm{X} 2=$ $43,33 ; \mathrm{p}<0.0001)$ and also of the dens destruction and the radiographic stage of $\mathrm{RA}$ of the hands $(\mathrm{X} 2=67,63 ; \mathrm{p}<$ $0,0001)$ and of the feet $(\mathrm{X} 2=38,84 ; \mathrm{p}<0,0001)$. The associations of cervical spine involvement with positive rheumatoid factor, sex were not significant.

Conclusion Destruction of dens ephistrophei correlates both, with the hands and feet radiographic stages; the correlation with the feet involvement was less pronounced. There was no significant difference in cervical spine involvement by sex or rheumatoid factor presence. The vertical and the lateral subluxations were found only in the combinations with the ventral subluxations.

\section{THU0200 AUDIT OF ORTHOPAEDIC OPERATIONS AND POSTOPERATIVE COMPLICATIONS IN RHEUMATOLOGY PATIENTS. RESULTS FROM 7 CENTRES}

${ }^{1} \mathrm{~F}$ Yuksel, ${ }^{2} \mathrm{~J}$ Griffin, ${ }^{3} \mathrm{~A}$ Kola, ${ }^{4} \mathrm{H}$ Sinclair, ${ }^{1} \mathrm{~A}$ Young, ${ }^{1} \mathrm{C}$ Mayes. ${ }^{1}$ Rheumatology, Rheumatology Audit Group, St Albans; ${ }^{2}$ Rheumatology, Chase Farm, Enfield; ${ }^{3}$ Rheumatology, Watford General, Watford; ${ }^{4}$ Rheumatology, North Middlesex, London, UK

\subsection{6/annrheumdis-2001.1102}

Background Waiting times for surgery, post-operative hospital inpatient stays and complication rates vary between hospitals. A regional audit group in rheumatology has conducted a survey to compare services for rheumatology patients.

Objectives To compare operation waiting times, post operative complication rates and management of rheumatology drug therapies during inpatient stays for rheumatolgy patients. 
Methods Rheumatologists from seven hospitals completed an audit form on consecutive patients in rheumatology outpatient departments over six months. Information on details of all orthopaedic procedures, waiting times, inpatient stays, complications, concurrent rheumatological drug therapies was obtained from medical records and from patients themselves (inflammatory joint disease was primary diagnosis in $81 \%$ ).

Results A total of 406 orthopaedic operations were performed in 293 patients, 106 total knee replacements (26\%), 71 total hip replacements (17.5\%), 48 wrist/hand joint operations (12\%), 27 forefoot arthroplasties (6.7\%), 15 shoulder replacements (3.7\%), 14 elbow replacements (3.4\%), 12 ankle fusions (3\%) and the remainder miscellaneous.

The main post operative complications which resulted in increased lenght of inpatient stay were wound sepsis (17), chest infection (4), deep vein thrombosis (4) joint dislocation/fracture (3). Main second line drugs were sulphasalzine (65) and methotrexate (58) and steroids were used by 39 patients. Figures will show differences between centres for waiting times (median 9 months) and inpatient stays (median 7 days).

Conclusion Marked variations in waiting times could be identified to specific local difficulties which are being addressed. Cessation or changes in second line drugs were uncommon and created only short lasting problems, but need to be reviewed regularly.

\section{THU0201 ABILITY OF THE LABORATORY TESTS TO PREDICT RHEUMATOID ARTHRITIS IN PATIENTS WITH EARLY ARTHRITIS}

A Saraux, JM Berthelot, G Chales, C Le Henaff, JY Mary, JB Thorel, S Hoang, M Dueymes, V Devauchelle, D Baron, P Le Goff, P Youinou. Rheumatology, Brest University Medical School, Brest, France

10.1136/annrheumdis-2001.1103

\section{Background}

Objectives To determine the diagnostic value in early rheumatoid arthritis (RA) of various laboratory tests used alone or in combination.

Methods A cohort of 270 patients with early arthritis was constituted between 1995 and 1997 in seven hospitals in Brittany (France). Each patients underwent at first visit a standardised examination, laboratory tests [rheumatoid factors (RF), the functionnal affinity of IgM-rheumatoid factors, antiperinuclear factor, IgG, IgM and IgA antikeratin antibody (AKA), antiRA33 antibody, antinuclear antibodies, ELISA analysis of IgG glycosylation, circulating immune complexes, $\operatorname{IgG} 1, \operatorname{IgG} 2, \operatorname{IgG} 3$, and $\operatorname{IgG}$ 4, and HLA AB DR typing], and radiographs. They were examined in the same way at six-month intervals until their last visit between June and December 1999, when the diagnosis of RA was made by a panel of five rheumatologists. Ninety-eight (38\%) patients were considered as having RA at their final visit. The ability of each test as measured at the initial visit to discriminate between RA and non RA patients was evaluated through sensitivity and specificity. Optimal cutoff for continuous test was derived from Received Operating Characteristic curve. Multiple logistic regression was used to select combination of laboratory tests able to discriminate between RA and non RA patients and the diagnostic value of these combination was evaluated through sensitivity and specificity.

Results The performance of the combinations using either the pair with the best diagnostic value combined with a third selected laboratory test or multiple logistic regression demonstrated that high levels of IgM RF by ELISA, IgG AKA, and latex test had the strongest association to RA.

Conclusion IgM-RF by ELISA, IgG-AKA, and the latex test are the best laboratory tests for discriminating between patients with and without RA. The other biological tests did not improve the diagnostic value.

\section{THU0202 PATTERN OF RADIOGRAPHIC DAMAGE OF THE HAND JOINTS IN RHEUMATOID ARTHRITIS: A STUDY OF 193 PATIENTS}

LS Ines, P Reis, MJ Santos, M Alexandre, C Silva, A Branha, A Figueiredo, D Nour, JA Da Silva, A Malcata, A Porto. Rheumatology Department, University Hospital of Coimbra, Coimbra, Portugal

\subsection{6/annrheumdis-2001.1104}

Background Metacarpophalangeal (MCP) and proximal interphalangeal (PIP) joints of the hands are some of the most frequently involved areas in rheumatoid arthritis (RA). However, observational data suggest that differences may exist between different fingers.

Objectives To evaluate the pattern of radiographic damage of the wrists and small joints of the hands in RA patients.

Methods Cross-sectional study of 193 RA patients, fulfilling the 1987 ACR criteria (female $=168$ [87\%], male $=25$ [13\%]; mean age $=57.0 \pm 11.7$ years; mean disease duration $=13.4$ \pm 8.1 years; RF positive $=72 \%$ ). They attended consecutively our hospital-based outpatient rheumatology clinic. Radiographs of the hands were obtained from all patients. Wrists, MCP, PIP and distal interphalangeal joints (DIP) were scored using Larsen's method. All radiographs were evaluated by a single reader in a blinded fashion. The intrarreader concordance rate was $>0.82$ for all joints.

Results Mean Larsen scores were $2.25 \pm 1.54$ for wrists, $1.70 \pm$ 1.49 for MCPs, $1.29 \pm 1.19$ for PIPs and $0.84 \pm 0.74$ for DIPs. There were erosive changes in $62.7 \%$ of the wrists, $39.0 \%$ of the MCPs, $27.4 \%$ of the first finger interphalangeals, $20.8 \%$ of the PIPs and $10.3 \%$ of the DIPs. Mean scores for each joint area and for each finger are presented in the Table 1 below.

\begin{tabular}{llllll}
\multicolumn{6}{l}{ Abstract THU0202 Table 1} \\
\hline & Finger 1 & Finger $\mathbf{2}$ & Finger $\mathbf{3}$ & Finger $\mathbf{4}$ & Finger $\mathbf{5}$ \\
\hline MCP & $1.73 \pm 1.36$ & $1.91 \pm 1.60$ & $1.74 \pm 1.49$ & $1.53 \pm 1.37$ & $1.62 \pm 1.46$ \\
PIP & $1.37 \pm 1.20$ & $1.53 \pm 1.35$ & $1.20 \pm 1.16$ & $1.20 \pm 1.12$ & $1.15 \pm 1.10$ \\
DIP & N/A & $0.81 \pm 0.79$ & $0.92 \pm 0.84$ & $0.82 \pm 0.69$ & $0.82 \pm 0.66$ \\
\hline
\end{tabular}

Conclusion Mean radiographic damage increases from DIPs to proximal joints up to the wrist. There are also differences of the damage of each joint area between fingers. Functional and mechanical factors may contribute to these differences.

\section{THU0203 INCIDENCE OF CHLOROQUINE RETINOPAHY IN RHEUMATOID ARTHRITIS PATIENTS}

1J Gonzalez-Dominguez, ${ }^{2} \mathrm{M}$ Santos, ${ }^{1} \mathrm{~A}$ Escudero, ${ }^{1} \mathrm{~A}$ Cisnal, ${ }^{1} \mathrm{M}$ Romero, ${ }^{1} \mathrm{~V}$ Perez, ${ }^{1} \mathrm{MD}$ Lopez, ${ }^{1} \mathrm{MA}$ Caracuel, ${ }^{1} \mathrm{FG}$ Martinez, ${ }^{2} \mathrm{JM}$ Gallardo, ${ }^{1} \mathrm{E}$ Collantes. ${ }^{1}$ Rheumatology; ${ }^{2}$ Ophthalmology, Hospital Universitario Reina Sofia, Cordoba, Spain

10.1136/annrheumdis-2001.1105 